\title{
A narrative review: depth of response as a predictor of the long- term outcomes for solid tumors
}

\author{
Xiaohui Xie ${ }^{1,2 \#}, \mathrm{Xin} \mathrm{Li}^{1 \#}$, Wenxiu Yao ${ }^{1 \#}$ \\ ${ }^{1}$ University of Electronic Science and Technology of China, Sichuan Cancer Hospital and Institute \& Cancer, The Second People's Hospital of \\ Sichuan Province, Chengdu, China; ${ }^{2}$ Chengdu Medical College, Chengdu, China \\ Contributions: (I) Conception and design: All authors; (II) Administrative support: None; (III) Provision of study materials or patients: None; (IV) \\ Collection and assembly of data: All authors; (V) Data analysis and interpretation: All authors; (VI) Manuscript writing: All authors; (VII) Final \\ approval of manuscript: All authors. \\ "These authors contributed equally to this work. \\ Correspondence to: Wenxiu Yao, PhD. Department of Oncology, Affiliated Cancer Hospital of Medical School, University of Electronic Science and \\ Technology of China, Sichuan Cancer Hospital and Institute \& Cancer, The Second People's Hospital of Sichuan Province, Chengdu 610041, \\ China. Email: redixh@163.com.
}

\begin{abstract}
Response Evaluation Criteria in Solid Tumors (RECIST 1.1) is classical and popular for public. However, there are some problems recently. For example, partial response ranges from $30 \%$ to $99 \%$, objective response is dichotomous, so there may be some heterogeneity. New metrics for evaluating the efficacy have been investigating, such as early tumor shrinkage, time to response and depth of response (DpR). $\mathrm{DpR}$ has been used in hematologic malignancies and is considered as a predictor of efficiency. In solid tumors, DpR was firstly proposed by Mansmann et al. in metastatic colorectal cancer (mCRC) and defined as the percentage of tumor shrinkage, which is a continuous metric, and could avoid the information loss due to dichotomization of responses that has been widely applied to several kinds of solid tumors. Some authors have found associations between DpR and OS, DpR is a valuable surrogate endpoint for mCRC, metastatic breast cancer, metastatic melanoma and advanced pancreatic cancer. However, the predictive value of $\mathrm{DpR}$ is still uncertain in the research of lung cancer and gastric cancer. Which indicating that a mature and unified application standard has not yet been formed for $\mathrm{DpR}$. This article summarizes researches on the $\mathrm{DpR}$ as a predictor of the long-term outcomes for solid tumors, it also discusses the challenges and limitations in the applications of DpR.
\end{abstract}

Keywords: Solid tumors; depth of response; efficacy evaluation

Submitted Jul 17, 2020. Accepted for publication Dec 18, 2020.

doi: $10.21037 /$ tcr-20-2547

View this article at: http://dx.doi.org/10.21037/tcr-20-2547

\section{Introduction}

According to statistics, there were 18.1 million new diagnoses and 9.6 million deaths of malignant tumors worldwide in 2018. The top five incidence are lung cancer, female breast cancer, prostate cancer, colorectal cancer, and gastric cancer. Meanwhile, the top five mortality rates are lung cancer, colorectal cancer, gastric cancer, liver cancer, and breast cancer (1). With the increase of tumor incidence and mortality, treatments for tumors are also constantly updating, from traditional treatment such as surgical resection, chemotherapy and radiotherapy, to individualized treatment, such as endocrine therapy, targeted therapy, immunotherapy, etc. As these treatments expanding in scope, the criteria for evaluating their effectiveness are updating. RECIST 1.1 is currently the most accepted standard for evaluating the efficacy of solid tumors (2). In evaluating the therapeutic effects of cancer, objective response rate (ORR) is an effective surrogate endpoint for overall survival 
(OS) defined by RECIST 1.1, and widely used in clinical treatment. Nonetheless, clinical studies conducted by Gadgeel et al. (3) and Aix et al. (4) have indicated that ORR may not be able to adequately access therapeutic effects, which is not always related to progress free survival (PFS) or OS consistent. ORR is not a continuous metric, partial response ranges from $30 \%$ to $99 \%$, this range is very wide and there may be some inaccuracies. RECIST 1.1 based on the change of tumor shrinkage, tumor shrinkage as a predictor have some limitations. First, tumor shrinkage measurements are based on the sum of the longest diameters of measurable target lesions, but non-measurable lesions cannot be considered. The reduction in the target lesions does not always result in a diameter reduction, because the tumor tissue can be replaced by necrotic or fibrous tissue, and these morphological changes cannot be accurately identified by computed tomography. Second, tumor shrinkage may not always be symmetrical, which may affected the measure of target lesions. Third, tumors metabolic response reflects the viability of neoplastic cells and correlated with patient outcome, 18F-FDGPET CT can detect early metabolic changes in tumor cell metabolism before any change in tumor size occurs (5). In addition, the functional status of organ, the symptoms and subjective feelings of patients are also important. So, many factors need to be considered in predicting the prognosis of patients.

DpR has been used in hematologic malignancies and is considered as a predictor of efficiency. In multiple myeloma, DpR relate with $M$ protein in the blood and urine and plasma cells, DpR can be used as a predictor for prognosis of non-solid tumor (6). In solid tumors, Mansmann et al. firstly proposed $\mathrm{DpR}$ as a surrogate endpoint in metastatic colorectal cancer (mCRC), and defined $\mathrm{DpR}$ as the maximum rate of reduction from the initial tumor burden (7). In 2015, Heinemann et al. conducted a systematic analysis of $\mathrm{DpR}$ as a measure of efficacy in three experiments, they realized that $\mathrm{DpR}$ can be a potential surrogate endpoint for mCRC patient (8). After that, researchers were inspired to study $\mathrm{DpR}, \mathrm{DpR}$ has been applied in several kinds of solid tumors, for example, mCRC, lung cancer, gastric cancer, metastatic breast cancer, metastatic melanoma and advanced pancreatic cancer. $\mathrm{DpR}$ is a valuable surrogate endpoint for mCRC patients received anti-EGFR antibody, but the predictive value of $\mathrm{DpR}$ in other solid tumors need further studies. This review will summarize the application value of $\mathrm{DpR}$ in common solid tumors, aim to provide references for future clinical therapy.

We present the following article in accordance with the Narrative Review reporting checklist (available at http:// dx.doi.org/10.21037/tcr-20-2547).

\section{Methods}

The titles and abstracts or the full articles in the PubMed, Cochrane and CNKI databases were searched using the following search terms in titles and abstracts: 'depth of response' OR 'deepness of response'. No language restriction was applied to the literature search and the search was limited to studies in humans. Original articles from 1987 through June, 2020 that reported randomized controlled trials (RCTs) that involve depth of response or deepness of response and solid tumors were included in this study. Articles not fulfilling all these criteria were excluded.

\section{Application of $D p R$ in colorectal cancer}

Colorectal cancer is one of the most common malignancies, its mortality rate is second only to that of lung cancer, approximately a quarter of patients have already undergone distant organ metastasis at the time of initial diagnosis and cannot be treated by surgery (9). The treatment for patients with mCRC mainly includes chemotherapy with or without molecular targeting biologics, which can lower the clinical stage and add the opportunity to surgery (10-12). PFS and OS for patients with mCRC have been improved because of the combination of chemotherapy and molecular targeting biologics in the first-line treatment, such as cetuximab, panizumab and bevacizumab (13-15). As the median OS of patients is prolonged, the design of clinical trials and the choice of treatment regime urgently need an early alternative endpoint for OS, which promotes the proposal and application of DpR. Many studies about mCRC confirmed the predictive value of $\mathrm{DpR}$ in mCRC.

\section{Application of DpR in the chemotherapy combined with EGFR inbibitors for $m C R C$}

Mansmann et al. first proposed the definition of $\mathrm{DpR}-$ the maximum percentage of reduction from the initial tumor burden in 2013 (7). Through their analysis of CRYSTAL (16) and OPUS (17) clinical trials, they found that the combination of cetuximab and chemotherapy can obtain higher DpR and longer post progression survival (PPS), and OS, which emphasized that DpR can be used 
as a new efficacy evaluation for clinical trials. Similar explorations have been carried out, and four reports (18-21) showed that DpR can predict the prognosis of RAS wild type mCRC patients receiving first-line chemotherapybased cetuximab. In 2016, Tsuji et al. analyzed 54 patients who received FOLFOX combined with Cetuximab in JACCRO CC-05 phase II clinical trial, median DpR was $56.3 \%$. DpR was related to OS and PPS (OS: rs=0.314, $\mathrm{P}=0.027$; PPS: $\mathrm{rs}=0.366, \mathrm{P}=0.017$ ) (19). Furthermore, Sunakawa $e t$ al. collected 92 patients in JACCRO CC-05 and JACCRO CC-06 Phase II clinical trials, they found a correlation between CEA levels and DpR ( $r s=0.44$, $\mathrm{P}<0.0001$ ), and both $\mathrm{DpR}$ and CEA levels are related to clinical results of cetuximab first-line therapy (18).

$\mathrm{DpR}$ also showed its predictive value in the mCRC patients who received second-line chemotherapy with cetuximab. Osumi et al. published a report about 42 mCRC patients who received second-line FOLFIRI-based cetuximab, results showed that patients with DpR $>30 \%$ have longer OS and PFS (22), firstly proving that DpR can be used as a new indicator of the efficacy for second-line treatment of mCRC.

In addition to cetuximab, another EGFR antibodyPanizumab can also improve the DpR of RAS wild-type mCRC patients. Taieb et al. (23) conducted an exploratory analysis on PRIME (24), PEAK (25), and PLANET (26) trials to assess the impact of DpR on survival outcomes in patients with RAS wild-type mCRC received panitumumab. These results all suggested that $\mathrm{DpR}$ is correlated with PFS and OS (Table 1).

\section{Application of DpR in the chemotherapy for colorectal cancer}

In order to evaluate whether DpR is universally applicable to chemotherapy alone for mCRC, Nozawa et al. (27) conducted a study that consisted of $156 \mathrm{mCRC}$ patients who received first-line chemotherapy regimens, FOLFOX (5-fluorouracil, leucovorin, and oxaliplatin), CapeOX (capecitabine and oxaliplatin), or FOLFIRI (5-fluorouracil, leucovorin, and irinotecan). The study divided patients into two groups according to $\mathrm{DpR}<45 \%$ and $\mathrm{DpR} \geq 45 \%$. It indicated that patients whose $\mathrm{DpR} \geq 45 \%$ was correlated with longer PFS (median 16.4 vs. 8.1 months for DpR $<45 \%, \mathrm{P}=0.006$ ) and OS (median 58.6 vs. 30.9 months for $\mathrm{DpR}<45 \%, \mathrm{P}=0.041)$. Similar results were also obtained in Kim et al.'s (28) retrospective study of patients receiving chemotherapy alone. PFS, OS, and PPS of patients with $\mathrm{DpR} \geq 60 \%$ were significantly improved.

\section{Application of $D p R$ in the combination of chemotherapy and Bevacizumab for colorectal cancer}

The TRIBE phase III trial compared the efficacy of firstline FOLFOXIRI plus bevacizumab with FOLFIRI plus bevacizumab for unresectable mCRC patients, demonstrating that FOLFOXIR pus bevacizumab arm had a higher $\mathrm{DpR}$ (43.4\% vs. 37.8\%, $\mathrm{P}=0.003)$, longer PFS (9.2 vs. 7.2 months, $\mathrm{P}=0.024)$, and longer OS (30.4 vs. 26.9 months, $\mathrm{P}=0.213)$ than the other group, which firstly certified that DpR is associated with PFS, PPS and OS in these patients receiving chemotherapy-based bevacizumab (29).

However, there are still some limitations of these studies. Most of these research results were retrospective analysis and had not considered some factors that would affect efficacy, for example, primary tumor location (30-32) and BRAF mutation status (33-35). The optimal cut-off value of $\mathrm{DpR}$ has no definite conclusion. Whether DpR can be used as a predictor of PFS and OS still needs to be confirmed by large-scale prospective studies.

\section{Application of DpR in lung cancer}

Lung cancer is the leading malignancy in morbidity and mortality. In recent years, researches on treatment with advanced lung cancer have become the main research direction of lung cancer. The emergence of targeted therapy and immunotherapy have improved the prognosis of advanced NSCLC. The prolongation of survival and the varies of tumor regression trend have promoting the exploration of new efficacy evaluation indicator. DpR has been applied to chemotherapy, targeted therapies and immunotherapy in patients with lung cancer. However, whether $\mathrm{DpR}$ can be used as an indicator for evaluating the efficacy of lung cancer is currently controversial.

\section{Application of $D p R$ in chemotherapy of lung cancer}

Chemotherapy plays an important role in the treatment of tumor. Before the advent of immunotherapy, chemotherapy was the commendatory treatment for advanced NSCLC without known driver mutations. For NSCLC, CA031 trial (36) divided patients into four groups based on the degree of DpR (Q1: $>0 \%$ to $25 \%$, Q2: $>25 \%$ to $50 \%$, 
Table 1 Application of DpR in colorectal cancer

\begin{tabular}{|c|c|c|c|c|}
\hline Patients & Regimen & Sample size & Outcomes & References \\
\hline KRAS WT mCRC & Chemotherapy + cetuximab & 92 & $\begin{array}{l}\text { Median DpR 50.4\%, correlation between } \mathrm{DpR} \text { and outcomes } \\
\text { (PFS: } r s=0.56, \mathrm{P}<0.0001 \text {; OS: } r \mathrm{~s}=0.39, \mathrm{P}=0.0090)\end{array}$ & $(18)$ \\
\hline KRAS WT MCRC & Chemotherapy + cetuximab & 76 & Median DpR 52\%, DpR correlated with OS and PFS & $(20)$ \\
\hline KRAS WT mCRC & Chemotherapy + cetuximab & 188 & Median DpR: $48.9 \%$, DpR correlated $(\mathrm{P}<0.0001)$ with OS & $(21)$ \\
\hline $\mathrm{mCRC}$ & $\begin{array}{l}\text { Second-lineChemotherapy } \\
+ \text { cetuximab }\end{array}$ & 112 & $\begin{array}{l}\text { FOLFIRI+cetuximab, correlation between } \mathrm{DpR} \text { and outcomes } \\
\text { (OS: } r=0.51, \mathrm{P}<0.001 \text {; PFS: } r=0.54, \mathrm{P}<0.001)\end{array}$ & $(22)$ \\
\hline KRAS WT MCRC & $\begin{array}{l}\text { Chemotherapy }+ \\
\text { panitumumab }\end{array}$ & 170 & $\begin{array}{l}\mathrm{DpR} \geq 30 \% \text { vs. }<30 \%, \mathrm{mPFS}[13.0 \text { vs. } 7.4 \text { months, HR } 2.80 \\
(95 \% \mathrm{Cl}, 1.86-4.23) ; \mathrm{P}<0.0001] ; \text { mOS (median } 37.4 \text { vs. } \\
17.3 \text { months, HR } 3.08 \text { (95\% Cl, } 2.01-4.71) ; \mathrm{P}<0.0001 \text { ) }\end{array}$ & $(23,25)$ \\
\hline KRAS WT mCRC & $\begin{array}{l}\text { Chemotherapy }+ \\
\text { panitumumab }\end{array}$ & 53 & $\begin{array}{l}\text { median DpR } 48 \% \text {, correlation between } \mathrm{DpR} \text { and outcomes } \\
\text { (PFS: Spearman Coefficient: }=0.53, \mathrm{P}<0.0001)(\mathrm{OS} \text { : Spearman } \\
\text { Coefficient }=0.51, \mathrm{P}<0.0002 \text { ) }\end{array}$ & $(23,26)$ \\
\hline $\mathrm{mCRC}$ & Chemotherapy & 156 & $\begin{array}{l}\text { Median DpR } 44.2 \%, \mathrm{DpR} \geq 45 \% \text { vs. }<45 \%, \text { mPFS ( } 16.4 \text { vs. } \\
8.1 \text { months, } \mathrm{P}=0.006) ; \text { mOS ( } 58.6 \text { vs. } 30.9 \text { months, } \mathrm{P}=0.041)\end{array}$ & $(27)$ \\
\hline $\mathrm{mCRC}$ & Chemotherapy & 242 & $\begin{array}{l}\text { median DpR } 38.5 \%, \mathrm{DpR} \geq 60 \% \text { vs. }<60 \% \text {, PFS ( } 11.6 \text { vs. } \\
4.8 \text { months, } \mathrm{P}<0.001) \text {; PPS ( } 18.4 \text { vs. } 10.1 \text { months, } \mathrm{P}<0.001) \text {; } \\
\text { OS (31.6 vs. } 17.2 \text { months; } \mathrm{P}<0.001)\end{array}$ & (28) \\
\hline
\end{tabular}

Q3: $>50 \%$ to $75 \%, \mathrm{Q} 4:>75 \%$ ), and these 4 groups were compared with a group in which patients who had no tumor shrinkage or tumor enlargement. Results show that $\mathrm{DpR}$ is closely related to PFS and OS of NSCLC patients receiving first-line platinum-based chemotherapy (Table 2) (37). Another retrospective analysis conducted by Qing et al. also obtained similar results, in which advanced non-squamous non-small cell lung cancer patients received paclitaxel carboplatin combined with bevacizumab (TCBev) regimen as first-line chemotherapy (44). The greater DpR is, the longer PFS lasts [DpR $<30 \%$ vs. $30 \% \leq \mathrm{DpR}<60 \%$ vs. DpR $\geq 60 \%$, PFS (10.6 vs. 8.2 vs. 6.4 months, $\mathrm{P}<0.001)$ ].

Small cell lung cancer (SCLC) is sensitive to radiotherapy and chemotherapy, and the tumor shrinks rapidly and greatly. In order to verify whether $\mathrm{DpR}$ is a predictive factor for survival outcome of patients with SCLC, Long et al. (38) conduct a retrospective analysis of patients with extensive SCLC who received first-line chemotherapy, results indicated that a greater $\mathrm{DpR}$ is associated with longer PFS and OS for patients, which proved that DpR is an independent prognostic factor for OS.

\section{Application of $D p R$ in targeted therapy of lung cancer}

Targeted therapies significantly prolong survival time and improve life quality of lung cancer. For example, the median PFS was 18.9 months and median OS was 38.6 months with osimertinib in untreated, EGFR-mutated advanced NSCLC (45); the median PFS were 34.8 months with alectinib in untreated ALK-positive advanced NSCLC (46). 
Table 2 Application of DpR in lung cancer

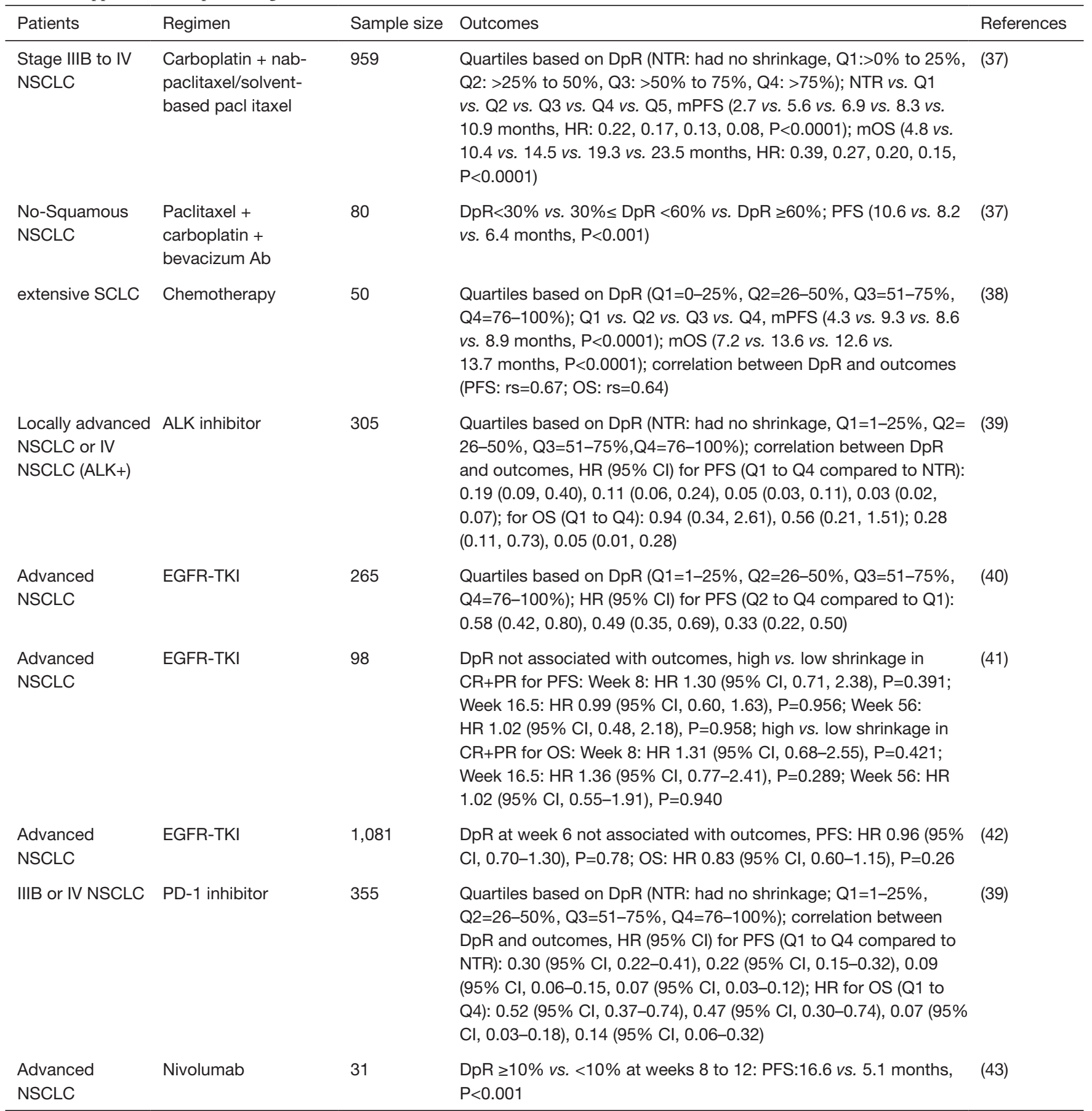

A retrospective research about EGFR-TKI and the other research about ALK-TKI for advanced NSCLC patients, these patients were classified into four groups according to the percentage of maximal tumor shrinkage $(\mathrm{Q} 1=1-25 \%$, $\mathrm{Q} 2=26-50 \%, \mathrm{Q} 3=51-75 \%$, and $\mathrm{Q} 4=76-100 \%), \mathrm{Q} 0 \mathrm{had}$ no shrinkage. The two trials suggested that $\mathrm{DpR}$ may be an additional outcome measure for clinical trials $(39,40)$. On the contrary, other researches showed that DpR cannot be used as a prognostic indicator for targeted therapy of lung cancer $(41,42)$. Wu et al. (41) analyzed patients with advanced EGFR mutation-positive NSCLC enrolled in first line gefitinib and afatinib trials. The study defined 
tumor shrinkage $\geq 30 \%$ as responders, then responders were categorized by the median DpR (49.5\%) into high and low shrinkage groups. No differences in PFS and OS were detected between the two groups at weeks $8,16.5$, and 56. It holds the view that DpR in responders was not predictive for PFS or OS. Lee et al. (42) analyzed data from 5 randomized trials (EURTAC, IPASS, ENSURE, LUXLung 3, and LUX-Lung 6 (47-51), and they also found that $\mathrm{DpR}$ was not associated with PFS and OS. The predictive role of $\mathrm{DpR}$ is still controversial in the application of targeted therapy for lung cancer.

\section{Application of DpR in immunotherapy of lung cancer}

Immune checkpoint inhibitors (ICIs) present a significant progress in oncology. Tumors respond differently to immunotherapies compared with cytotoxic drugs and targeted therapies, patterns of response and progression of ICIs differ from those seen with chemotherapeutic agents, raising questions about the assessment of changes in tumor burden (52-55). ORR and DCR defined by RECIST1.1 may have some deficiencies in evaluating the efficacy of immunotherapy.

In $2017, \mathrm{DpR}$ was firstly applied to evaluate the prognosis of patients with stage IIIB to IV NSCLC received ICIs. An exploratory analysis of two RCTs on PD-1 inhibitors indicated that patients with $50 \%$ tumor shrinkage may be the cut-off value for predicting benefits of immunotherapy (39). A report on the relationship between early DpR and survival outcomes in advanced NSCLC patients treated with nivolumab, indicated that patients whose $\mathrm{DpR} \geq 10 \%$ at the first evaluation (8-12 weeks after starting nivolumab) have longer PFS ( $\mathrm{DpR} \geq 10 \%$ vs. DpR $<10 \%$, PFS: 16.6 vs. 5.1 months, $\mathrm{P}<0.001)$. They proposed that the early tumor response classification based on the degree of DpR may not accurately predict the long-term prognosis of NSCLC patients treated with nivolumab, and the depth of tumor remission may have a good application prospect in clinical practice (43).

$\mathrm{DpR}$, as a predictor in targeted therapy and immunotherapy, is still controversial. The main reasons are as follows. Firstly, the patients included in the studies, Wu et al.'s study included patients with advanced EGFR mutationpositive NSCLC enrolled in first-line gefitinib and afatinib trials (41). In Lee et al.'s study (42), patients who died or had disease progression measured by RECIST prior to or at 6 weeks were excluded. Besides, the status of gene may have influence on patients with advanced NSCLC treated with EGFR-TKI, like the TP53. Second, the treatments were distinctive, afatinib have greater affinity for EGFR tyrosine kinase domain compared to first-generation EGFR-TKIs and its irreversible pan-ErBb inhibitory property can led to the different response pattern. Third, the design of the study, for example, Wu et al. observed the correlation between $\mathrm{DpR}$ and prognosis in patients who reached $\mathrm{PR}$, not all patients. In addition, the number of patients included is different, and small sample size is heterogeneous for statistical analysis. There are only 2 studies about the application of DpR in immunotherapy of lung cancer, new criteria for immunotherapy were developed, such as irRECIST, irRC, and imRECIST $(53,56,57)$, these results needed further exploration to confirm. The correlation between DpR and OS may be affected by the subsequent treatment (58). More clinical trials are required to confirm the predictive value of $\mathrm{DpR}$.

\section{Application of DpR in gastric cancer}

The incidence rate of gastric cancer ranks fifth among malignant tumors and the mortality rate of cancer ranks third worldwide. Human epidermal growth factor receptor 2 (HER2) is an important biomarker and key driver of tumorigenesis in gastric cancer (59). For HER2 positive advanced gastric cancer (AGC) patients, chemotherapy combined with trastuzumab is currently the recommended standard treatment (60).

There are 3 retrospective studies of HER2 positive (HER2+) AGC patients received chemotherapy with trastuzumab, which showed that $\mathrm{DpR}$ can be a significant predictor for HER2+ AGC patients (61-63). The DpR cutoff value ranged from $44 \%$ to $50 \%$ in these studies, these patients were grouped according to the DpR cut-off value, and the results showed that the prognosis of $\mathrm{DpR} \geq$ cut-off value group was better, which confirmed the predictive value of $\mathrm{DpR}$ in the first-line treatment by trastuzumab combined with chemotherapy for AGC patients. Lee et al. (61) retrospectively analyzed $368 \mathrm{CT}$ examinations of 61 patients with AGC. According to Youden's J index, the optimal cutoff value of $\mathrm{DpR}$ was determined to be $45 \%$. The analysis showed that PFS and OS of patients with DpR $\geq 45 \%$ were longer (Table 3). Predictive value of $\mathrm{DpR}$ is associated with targeted drugs and chemotherapy regimens $(8,65)$, Kadowaki et al. (62) didn't publish chemotherapy regimen and HER2 mutation status, which may affect the research 
Table 3 Application of DpR in gastric cancer

\begin{tabular}{|c|c|c|c|c|}
\hline Patients & Regimen & Sample size & Outcomes & References \\
\hline $\begin{array}{l}\text { Advanced gastric } \\
\text { cancer (HER2+) }\end{array}$ & $\begin{array}{l}\text { Chemotherapy + } \\
\text { Trastuzumab }\end{array}$ & 57 & $\begin{array}{l}\text { Median DpR } 56.8 \%, \mathrm{DpR} \geq 50 \% \text { vs. } \mathrm{DpR}<50 \%, \mathrm{mPFS}(9.8 \text { vs. } \\
4.1 \text { months, } \mathrm{P}<0.001) ; \text { mOS ( } 24.7 \text { vs. } 12.8 \text { months, } \mathrm{P}<0.001)\end{array}$ & (62) \\
\hline $\begin{array}{l}\text { Advanced gastric } \\
\text { cancer }\end{array}$ & Chemotherapy & 632 & $\begin{array}{l}\text { DpR cutoff values } 36.7 \% \text { for PFS, } 40.0 \% \text { for OS, DpR moderately } \\
\text { predicted PFS [C } \tau \text { index } 0.697(95 \% \mathrm{Cl}, 0.678-0.717)] \text { and OS }[\mathrm{C} \tau \\
\text { index } 0.644(95 \% \mathrm{Cl}, 0.622-0.663)]\end{array}$ & (64) \\
\hline
\end{tabular}

results.

In recent years, studies on the second-line therapy of gastric cancer have shown that the second-line therapy can prolong the survival of patients (66-68). Lee et al. (61) further analyzed subgroups of patients receiving secondline chemotherapy, indicating that $\mathrm{DpR}$ was correlated with PPS (HR $=0.844 ; 95 £ ¥ \mathrm{CI}, 0.712$ to 0.999). Osumi et al. (63) collected the clinical data of 286 patients with AGC who received first-line therapy, in which 186 patients with Her2+ AGC received chemotherapy combined with trastuzumab, and 100 patients with Her2 negative (Her2) received S-1 plus oxaliplatin (SOX) or S-1 plus cisplatin (SP). They found that the $\mathrm{DpR}$ and survival time in Her2+ group was better than that in the HER2 negative group. In the Her2+ group, DpR was associated with PFS and OS. In the Her2group, the median value of $\mathrm{DpR}$ was $24 \%$. DpR $\geq 24 \%$ was also associated with significantly longer PFS than DpR $<24 \%$, while DpR was not associated with OS (DpR $\geq 24 \%$ vs. $<24 \%$, PFS: 7.6 vs. 4.5 months, HR 0.63, $\mathrm{P}=0.01$; OS: 14.8 vs. 12.2 months, HR 0.87, $\mathrm{P}=0.48$ ). The G-SOX Phase III clinical trial (69) included 632 patients who received the first-line SOX regimen and CS regimen. The relationship between DpR and prognosis was analyzed. The results showed that DpR was correlated with PFS and OS (64), which was different from the results of Osumi et al.'s.

In the gastric cancer, DpR may become a new predictor for efficiency. However, the predictive value of $\mathrm{DpR}$ is not sure, which may be related to other factors, for example, the mutation status of HER2, treatment methods, and so on. At present, the ICI treatment in GC provided modest survival benefit, further research is needed in the future.

\section{Application of DpR in other solid tumors}

$\mathrm{DpR}$ is rarely reported in other solid tumors. A study analyzed the evaluation value of $\mathrm{DpR}$ in patients with BRAF V600 mutant metastatic melanoma who received vemurafenib with or without Cobimetinib. The study collected data from 4 clinical trials (brim-2, brim-3, brim-7 and coBRIM), which showed that higher DpR is associated with longer survival, and supported DpR as a new measure in addition to traditional clinical prognostic variables (70). In 2016, Kaga et al. (71) firstly reported the application of DpR to 59 advanced pancreatic cancer (APC) patients receiving oxaliplatin, irinotecan, fluorouracil and calcium folinate (FOLFIRINOX). They found that DpR was significantly but weakly associated with $\mathrm{OS}(\mathrm{rs}=0.18$, $\mathrm{P}=0.017$ ) and was not associated with PFS. In 2018, Vivaldi et al. (72) estimated the prognostic role of $\mathrm{DpR}$ in metastatic PC treated with FOLFIRINOX or gemcitabine with nabpaclitaxel (GemNab). The study showed that median DpR was $27.5 \%$, DpR $\geq 27.5 \%$ was significantly associated with better PFS (9.0 vs. 6.7 months, $\mathrm{P}<0.001)$ and OS $(14.3$ vs. 11.1 months, $\mathrm{P}=0.031)$. DpR could be a favorable efficacy outcome measure in advanced PC treated with first-line combination chemotherapy. Che's study about HER2positive metastatic breast cancer treated with trastuzumab, they suggested that DpR could be used as predictors of clinical outcomes in metastatic breast cancer patients treated with trastuzumab-based regimens in the first-line setting. They suggested the cutoff value of $\mathrm{DpR} \geq 40 \%$ to distinguish patients with favorable clinical outcomes (73).

At present, there is still a lack of application of $\mathrm{DpR}$ in 
other solid tumors, such as liver cancer, esophageal cancer and cervical cancer. The predictive value of $\mathrm{DpR}$ in more solid tumors can be further explored in the future.

\section{Discussion and conclusions}

DpR has been explored in the evaluation of the efficacy of various solid tumors. $\mathrm{DpR}$ is a valuable surrogate endpoint for mCRC patients, both in mCRC patients received first-line cetuximab, panitumumab or bevacizumab-based chemotherapy and in mCRC patients received secondline cetuximab-based chemotherapy. In addition, DpR could be an outcome measure in metastatic breast cancer, metastatic melanoma and APC in in existing research. DpR is a continuous metric, which could avoid the information loss due to dichotomization of responses and might provide an earlier indications of drug activity than time to PFS or OS, representing a more powerful and informative metric. However, the predictive value of $\mathrm{DpR}$ is still uncertain in the research of lung cancer and gastric cancer. Unified application standard hasn't been formed, and there are still some disputes and limitations. Firstly, some researches (74-76) reported that bias occurs when patients are categorized into good and bad responder groups at baseline and then survival in these groups is compared. There is a time window for tumor shrinkage. A longer time for the occurrence of a larger $\mathrm{DpR}$, which may prolong the PFS and OS of the patient. In addition, $\mathrm{DpR}$ is based on the measurement of tumor diameter, but the growth and remission of the tumor are not symmetrical. The imaging changes cannot fully reflect the state of the tumor. The author thinks that the time-dependent bias needs to be taken into account in future research. Secondly, researches on $\mathrm{DpR}$ in solid tumors is based on the data obtained by retrospective analysis which have many interferences, so prospective research is urgently needed. In addition, prognosis for tumor is relate to many factors, such as tumor cell's biological behaviors, status of some biomarkers, and so on. The ability of proliferation and invasion decide the speed of tumor growth and tumor heterogeneity. In the era of precision medicine, more and more attention are being paid to be concerned with the molecular level of DNA and epigenetics. DpR cannot be a single predictor for efficacy, we need to consider these factors all together. $\mathrm{DpR}$ may be a promising predictor in future clinical trials, $\mathrm{DpR}$ needs to be based on these existing prognostic prediction models for larger scale prospective trials and synchronous comparison with Recist1.1 to further explore the value of $\mathrm{DpR}$, to form a perfect application specification, guide clinical work, and improve patient prognosis.

\section{Acknowledgments}

We thank our friend Qinyi Liao, for her valuable advice and contribution to polish the manuscript.

Funding: None.

\section{Footnote}

Reporting Checklist: The authors have completed the Narrative Review reporting checklist. Available at http:// dx.doi.org/10.21037/tcr-20-2547

Conflicts of Interest: All authors have completed the ICMJE uniform disclosure form (available at http://dx.doi. org/10.21037/tcr-20-2547). The authors have no conflicts of interest to declare.

Ethical Statement: The authors are accountable for all aspects of the work in ensuring that questions related to the accuracy or integrity of any part of the work are appropriately investigated and resolved.

Open Access Statement: This is an Open Access article distributed in accordance with the Creative Commons Attribution-NonCommercial-NoDerivs 4.0 International License (CC BY-NC-ND 4.0), which permits the noncommercial replication and distribution of the article with the strict proviso that no changes or edits are made and the original work is properly cited (including links to both the formal publication through the relevant DOI and the license). See: https://creativecommons.org/licenses/by-nc-nd/4.0/.

\section{References}

1. Bray F, Ferlay J, Soerjomataram I, et al. Global cancer statistics 2018: GLOBOCAN estimates of incidence and mortality worldwide for 36 cancers in 185 countries. CA Cancer J Clin 2018;68:394-424.

2. Eisenhauer EA, Therasse P, Bogaerts J, et al. New response evaluation criteria in solid tumours: revised RECIST guideline (version 1.1). Eur J Cancer 2009;45:228-47.

3. Gadgeel S, Peters S, Mok T, et al. Alectinib versus crizotinib in treatment-naive anaplastic lymphoma kinasepositive (ALK+) non-small-cell lung cancer: CNS efficacy results from the ALEX study. Ann Oncol 2018;29:2214-22. 
4. Aix SP, Park K, Tan EH, et al. P1.34: First-Line Afatinib vs Gefitinib for Patients With EGFR Mutation-Positive Non-Small-Cell Lung Cancer: The LUX-Lung 7 Trial: Track: Advanced NSCLC. J Thorac Oncol 2016;11:s203-4.

5. Pinker K, Riedl C, Weber WA, et al. Evaluating tumor response with FDG PET: updates on PERCIST, comparison with EORTC criteria and clues to future developments. Eur J Nucl Med Mol Imaging 2017;44:55-66.

6. Kumar S, Paiva B, Anderson KC, et al. International Myeloma Working Group consensus criteria for response and minimal residual disease assessment in multiple myeloma. Lancet Oncol 2016;17:e328-46.

7. Mansmann UR, Sartorius U, Laubender RP, et al. Quantitative Analysis of the Impact of Deepness of Response on Post-Progression Survival Time Following First-Line Treatment in Patients with mCRC. Ann Oncol 2013;31:3630.

8. Heinemann V, Stintzing S, Modest DP, et al. Early tumour shrinkage (ETS) and depth of response (DpR) in the treatment of patients with metastatic colorectal cancer (mCRC). Eur J Cancer 2015;51:1927-36.

9. Van Cutsem E, Cervantes A, Nordlinger B, et al. Metastatic colorectal cancer: ESMO Clinical Practice Guidelines for diagnosis, treatment and follow-up. Ann Oncol 2014;25 Suppl 3:iii1-9.

10. Nordlinger B, Van Cutsem E, Gruenberger T, et al. Combination of surgery and chemotherapy and the role of targeted agents in the treatment of patients with colorectal liver metastases: recommendations from an expert panel. Ann Oncol 2009;20:985-92.

11. Van Cutsem E, Nordlinger B, Cervantes A. Advanced colorectal cancer: ESMO Clinical Practice Guidelines for treatment. Ann Oncol 2010;21:v93-7.

12. Schmoll HJ, Van Cutsem E, Stein A, et al. ESMO Consensus Guidelines for management of patients with colon and rectal cancer. A personalized approach to clinical decision making. Ann Oncol 2012;23:2479-516.

13. Brodowicz T, Ciuleanu TE, Radosavljevic D, et al. FOLFOX4 plus cetuximab administered weekly or every second week in the first-line treatment of patien ts with KRAS wild-type metastatic colorectal cancer: a randomized phase II CECOG study. Ann Oncol 2013;24:1769-77.

14. Douillard JY, Siena S, Cassidy J, et al. Final results from PRIME: randomized phase III study of panitumumab with FOLFOX4 for first-line treat ment of metastatic colorectal cancer. Ann Oncol 2014;25:1346-55.

15. Maiello E, Di Maggio G, Cordio S, et al. Bevacizumab in Combination With Either FOLFOX-4 or XELOX-2

in First-line Treatment of Patients With $\mathrm{M}$ etastatic Colorectal Cancer: A Multicenter Randomized Phase II Trial of the Gruppo Oncologico dell'I talia Meridionale (GOIM 2802). Clin Colorectal Cancer 2020;19:109-15.

16. Van Cutsem E, Kohne CH, Hitre E, et al. Cetuximab and chemotherapy as initial treatment for metastatic colorectal cancer. N Engl J Med 2009;360:1408-17.

17. Bokemeyer C, Bondarenko I, Makhson A, et al. Fluorouracil, leucovorin, and oxaliplatin with and without cetuximab in the first-line treatment of metastatic colorectal cancer. J Clin Oncol 2009;27:663-71.

18. Sunakawa Y, Tsuji A, Denda T, et al. CEA Response and Depth of Response (DpR) to Predict Clinical Outcomes of First-Line Cetuximab Treatment for Metastatic Colorectal Cancer. Target Oncol 2017;12:787-94.

19. Tsuji A, Sunakawa Y, Ichikawa W, et al. Early Tumor Shrinkage and Depth of Response as Predictors of Favorable Treatment Outcomes in Patients with Metastatic Colorectal Cancer Treated with FOLFOX Plus Cetuximab (JACCRO CC-05). Target Oncol 2016;11:799-806.

20. Kr A, P SS, Kumar C R. Assessing the impact of early tumour shrinkage and depth of response on survival outcomes in patients with RAS wild-type metastatic colorectal cancer. Ann Oncol 2019;30 Suppl 4:iv54.

21. Stintzing S, Modest DP, Rossius L, et al. FOLFIRI plus cetuximab versus FOLFIRI plus bevacizumab for metastatic colorectal cancer (FIRE-3): a post-hoc analysis of tumour dynamics in the final RAS wild-type subgroup of this randomised open-label phase 3 trial. Lancet Oncol 2016;17:1426-34.

22. Osumi H, Matsusaka S, Suenaga M, et al. Associations between deepness of response and clinical outcomes among Japanese patients with metastatic colorectal cancer treated with second-line FOLFIRI plus cetuximab. Onco Targets Ther 2015;8:2005-13.

23. Taieb J, Rivera F, Siena S, et al. Exploratory analyses assessing the impact of early tumour shrinkage and depth of response on survival outcomes in patients with RAS wild-type metastatic colorectal cancer receiving treatment in three randomised panitumumab trials. J Cancer Res Clin Oncol 2018;144:321-35.

24. Douillard JY, Siena S, Peeters M, et al. Impact of early tumour shrinkage and resection on outcomes in patients with wild-type RAS metastatic colorectal cancer. Eur J Cancer 2015;51:1231-42.

25. Rivera F, Karthaus M, Hecht JR, et al. Final analysis of the randomised PEAK trial: overall survival and tumour 
responses during first-line treatment with mFOLFOX6 plus either panitumumab or bevacizumab in patients with metastatic colorectal carcinoma. Int J Colorectal Dis 2017;32:1179-90.

26. Carrato A, Abad A, Massuti B, et al. First-line panitumumab plus FOLFOX4 or FOLFIRI in colorectal cancer with multiple or unresectable liver metastases: A randomised, phase II trial (PLANET-TTD). Eur J Cancer 2017;81:191-202.

27. Nozawa H, Nishikawa T, Tanaka T, et al. 'Deepness of Response' Is Associated with Overall Survival in Standard Systemic Chemotherapy for Metastatic Colorectal Cancer. Chemotherapy 2014;60:360-7.

28. Kim KR, Yoon JH, Shim HJ, et al. Role of depth of response and MTHFR genotype as predictors of fluorouracil rechallenge therapy for refractory metastatic colorectal cancer. Oncol Lett 2017;14:2491-8.

29. Cremolini C, Loupakis F, Antoniotti C, et al. Early tumor shrinkage and depth of response predict long-term outcome in metastatic colorectal cancer patients treated with first-line chemotherapy plus bevacizumab: results from phase III TRIBE trial by the Gruppo Oncologico del Nord Ovest. Ann Oncol 2015;26:1188-94.

30. Aggarwal H, Sheffield KM, Li L, et al. Primary tumor location and survival in colorectal cancer: A retrospective cohort study. World J Gastrointest Oncol 2020;12:405-23.

31. Zheng C, Jiang F, Lin H, et al. Clinical characteristics and prognosis of different primary tumor location in colorectal cancer: a population-based cohort study. Clin Transl Oncol 2019;21:1524-31.

32. Peeters $M$, Price T, Taieb J, et al. Relationships between tumour response and primary tumour location, and predictors of long-term survival, in patients with RAS wild-type metastatic colorectal cancer receiving firstline panitumumab the therapy: retrospective analyses of the PRIME and PEAK clinical trials. Br J Cancer 2018;119:303-12.

33. Jones JC, Renfro LA, Al-Shamsi HO, et al. Non-V600 BRAF Mutations Define a Clinically Distinct Molecular Subtype of Metastatic Colorectal Cancer. J Clin Oncol 2017;35:2624-30.

34. Lai E, Pretta A, Impera V, et al. BRAF-mutant colorectal cancer, a different breed evolving. Expert Rev Mol Diagn 2018;18:499-512.

35. Zhang J, Wang X, Shen L. Impacts of microsatellite status, RAS and BRAF mutation on postoperative follow-up strategy in stage II and III colorectal cancer. Zhonghua Wei Chang Wai Ke Za Zhi 2018;21:716-20.
36. Socinski MA, Bondarenko I, Karaseva NA, et al. Weekly nab-paclitaxel in combination with carboplatin versus solvent-based paclitaxel plus carboplatin as first-line therapy in patients with advanced non-small-cell lung cancer: final results of a phase III trial. J Clin Oncol 2012;30:2055-62.

37. Morgensztern D, Ko A, O'Brien M, et al. Association between depth of response and survival in patients with advanced-stage non-small cell lung cancer treated with first-line chemotherapy. Cancer 2019;125:2394-9.

38. Long X, Guanzhong Z, Xiaodong X, et al. Correlation between depth of tumour response and survival in extensive stage SCLC. Modern Oncology 2019;27:591-4.

39. McCoach CE, Blumenthal GM, Zhang L, et al. Exploratory analysis of the association of depth of response and survival in patients with metastatic non-small-cell lung cancer treated with a targeted therapy or immunotherapy. Ann Oncol 2017;28:2707-14.

40. Liu YT, Zhang K, Li CC, et al. Depth of Response was Associated with Progression-Free Survival in Patients with Advanced Non-small Cell Lung Cancer treated with EGFR-TKI. J Cancer 2019;10:5108-13.

41. Wu TH, Hsiue E, Lee JH, et al. MA08.05 Depth of Response to First-Line EGFR TKI Does Not Predict Survival in EGFR-Mutated NSCLC Patients. J Thorac Oncol 2017;12:s386-7.

42. Lee CK, Lord S, Marschner I, et al. The Value of Early Depth of Response in Predicting Long-Term Outcome in EGFR-Mutant Lung Cancer. J Thorac Oncol 2018;13:792-800.

43. Kawachi H, Fujimoto D, Morimoto T, et al. Early depth of tumor shrinkage and treatment outcomes in non-small cell lung cancer treated using Nivolumab. Invest New Drugs 2019;37:1257-65.

44. Qing C, Jialin Q, Yanwei Z, et al. Correlation of Survival with Therapy Effect, Depth of Response in Patients with Advanced No-Squamous Non-Small Cell Lung Cancer Following Chemotherapy. Journal of Chinese Oncology 2019;25:793-7.

45. Soria JC, Ohe Y, Vansteenkiste J, et al. Osimertinib in Untreated EGFR-Mutated Advanced Non-Small-Cell Lung Cancer. N Engl J Med 2018;378:113-25.

46. Camidge DR, Dziadziuszko R, Peters S, et al. Updated Efficacy and Safety Data and Impact of the EML4-ALK Fusion Variant on the Efficacy of Alectinib in Untreated ALK-Positive Advanced Non-Small Cell Lung Cancer in the Global Phase III ALEX Study. J Thorac Oncol 2019;14:1233-43. 
47. Mok TS, Wu YL, Thongprasert S, et al. Gefitinib or carboplatin-paclitaxel in pulmonary adenocarcinoma. N Engl J Med 2009;361:947-57.

48. Sequist LV, Yang JC, Yamamoto N, et al. Phase III study of afatinib or cisplatin plus pemetrexed in patients with metastatic lung adenocarcinoma with EGFR mutations. J Clin Oncol 2013;31:3327-34.

49. $\mathrm{Wu} \mathrm{YL}, \mathrm{Zhou} \mathrm{C}, \mathrm{Hu} \mathrm{CP}$, et al. Afatinib versus cisplatin plus gemcitabine for first-line treatment of Asian patients with advanced non-small-cell lung cancer harbouring EGFR mutations (LUX-Lung 6): an open-label, randomised phase 3 trial. Lancet Oncol 2014;15:213-22.

50. Rosell R, Carcereny E, Gervais R, et al. Erlotinib versus standard chemotherapy as first-line treatment for European patients with advanced EGFR mutation-positive non-small-cell lung cancer (EURTAC): a multicentre, open-label, randomised phase 3 trial. Lancet Oncol 2012;13:239-46.

51. Wu YL, Zhou C, Liam CK, et al. First-line erlotinib versus gemcitabine/cisplatin in patients with advanced EGFR mutation-positive non-small-cell lung cancer: analyses from the phase III, randomized, open-label, ENSURE study. Ann Oncol 2015;26:1883-9.

52. Borcoman E, Nandikolla A, Long G, et al. Patterns of Response and Progression to Immunotherapy. Am Soc Clin Oncol Educ Book 2018;38:169-78.

53. Seymour L, Bogaerts J, Perrone A, et al. iRECIST: guidelines for response criteria for use in trials testing immunotherapeutics. Lancet Oncol 2017;18:e143-52.

54. Aykan NF, Zatl T. Objective response rate assessment in oncology: Current situation and future expectations. World J Clin Oncol 2020;11:53-73.

55. Inno A, Lo Russo G, Salgarello M, et al. The evolving landscape of criteria for evaluating tumor response in the era of cancer immunotherapy: From Karnofsky to iRECIST. Tumori 2018;104:88-95.

56. Wolchok JD, Hoos A, O'Day S, et al. Guidelines for the evaluation of immune therapy activity in solid tumors: immune-related response criteria. Clin Cancer Res 2009;15:7412-20.

57. Hodi FS, Ballinger M, Lyons B, et al. ImmuneModified Response Evaluation Criteria In Solid Tumors (imRECIST): Refining Guidelines to Asses s the Clinical Benefit of Cancer Immunotherapy. J Clin Oncol 2018;36:850-8.

58. Gettinger S, Horn L, Jackman D, et al. Five-Year FollowUp of Nivolumab in Previously Treated Advanced NonSmall-Cell Lung Cancer: Results From the CA209-003
Study. J Clin Oncol 2018;36:1675-84.

59. Gravalos C, Jimeno A. HER2 in gastric cancer: a new prognostic factor and a novel therapeutic target. Ann Oncol 2008;19:1523-9.

60. Bang YJ, Van Cutsem E, Feyereislova A, et al. Trastuzumab in combination with chemotherapy versus chemotherapy alone for treatment of HER2-positive advanced gastric or gastro-oesophageal junction cancer (ToGA): a phase 3, open-label, randomised controlled trial. Lancet 2010;376:687-97.

61. Lee CK, Kim SS, Park S, et al. Depth of response is a significant predictor for long-term outcome in advanced gastric cancer patients treated with trastuzumab. Oncotarget 2017;8:31169-79.

62. Kadowaki S, Masuishi T, Eto T, et al. Depth of response predicts the clinical outcome of advanced HER2positive gastric cancer to trastuzumab-based firstline chemotherapy. Cancer Chemother Pharmacol 2017;80:807-13.

63. Osumi H, Takahari D, Shinozaki E, et al. Associations between early tumor shrinkage and depth of response and clinical outcomes in patients treated with 1st-line chemotherapy for advanced gastric cancer. Gastric Cancer 2018;21:267-75.

64. Nishina T, Azuma M, Nishikawa K, et al. Early tumor shrinkage and depth of response in patients with advanced gastric cancer: a retrospective analysis of a randomized phase III study of first-line S-1 plus oxaliplatin vs. S-1 plus cisplatin. Gastric Cancer 2019;22:138-46.

65. Stintzing S, Fischer von Weikersthal L, Decker T, et al. FOLFIRI plus cetuximab versus FOLFIRI plus bevacizumab as first-line treatment for patients with metastatic colorectal cancer-subgroup analysis of patients with KRAS: mutated tumours in the randomised German AIO study KRK-0306. Ann Oncol 2012;23:1693-9.

66. Satake H, Sagawa T, Fujikawa K, et al. Phase Ib study of irinotecan and ramucirumab for advanced gastric cancer previously treated with fluoropyrimidine with/without platinum and taxane. Cancer Chemother Pharmacol 2018;82:839-45.

67. Bando H, Shimodaira H, Fujitani K, et al. A phase II study of nab-paclitaxel in combination with ramucirumab in patients with previously treated advanced gastric cancer. Eur J Cancer 2018;91:86-91.

68. Schmalenberg H, Al-Batran SE, Pauligk C, et al. CabaGast: multicentre, Phase II study with cabazitaxel in previously treated patients with advanced or metastatic adenocarcinoma of the esophagogastric junction and 
stomach. J Cancer Res Clin Oncol 2018;144:559-69.

69. Yamada Y, Higuchi K, Nishikawa K, et al. Phase III study comparing oxaliplatin plus S-1 with cisplatin plus S-1 in chemotherapy-naive patients with advanced gastric cancer. Ann Oncol 2015;26:141-8.

70. Lewis KD, Larkin J, Ribas A, et al. Impact of depth of response on survival in patients treated with cobimetinib \pm vemurafenib: pooled analysis of BRIM2, BRIM-3, BRIM-7 and coBRIM. Br J Cancer 2019;121:522-8.

71. Kaga Y, Sunakawa Y, Kubota Y, et al. Early tumor shrinkage as a predictor of favorable outcomes in patients with advanced pancreatic cancer treated with FOLFIRINOX. Oncotarget 2016;7:67314-20.

72. Vivaldi C, Cappelli C, Donati F, et al. Analysis of early tumor shrinkage and depth of response in metastatic pancreatic cancer patients treated with first-line modified

Cite this article as: $\mathrm{Xie} \mathrm{X}, \mathrm{Li} \mathrm{X}, \mathrm{Yao} \mathrm{W}$. A narrative review: depth of response as a predictor of the long-term outcomes for solid tumors. Transl Cancer Res 2021;10(2):1119-1130. doi: $10.21037 /$ tcr-20-2547
FOLFIRINOX or gemcitabine + nab-paclitaxel. Ann Oncol 2018;29 Suppl 5:v44.

73. Che YQ, Zhang Y, Ou KP, et al. Depth of Response and Early Tumor Shrinkage for Predicting Clinical Outcomes in HER2-Positive Metastatic Breast Cancer Treated with Trastuzumab. Cancer Manag Res 2020;12:8527-34.

74. Anderson JR, Cain KC, Gelber RD. Analysis of survival by tumor response and other comparisons of time-to-event by outcome variables. J Clin Oncol 2008;26:3913-5.

75. van Walraven C, Davis D, Forster AJ, et al. Timedependent bias was common in survival analyses published in leading clinical journals. J Clin Epidemiol 2004;57:672-82.

76. Gill BS, Flickinger JC, Beriwal S. Caveat for Immortal Time Bias in Adjuvant Therapy-Related Population-Based Analyses. J Clin Oncol 2015;33:2931. 